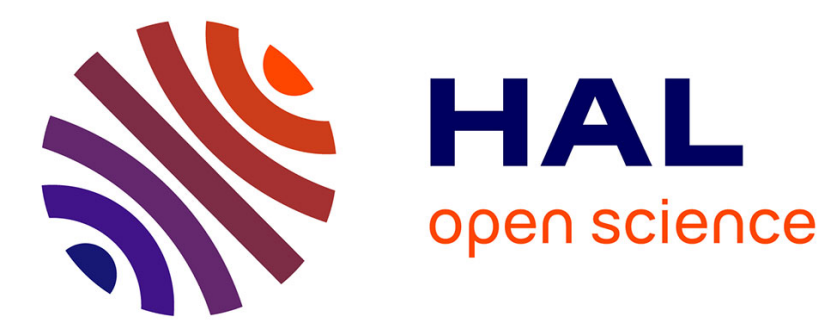

\title{
Experimental Descriptors for the Synthesis of Multicationic Nickel Perovskite Nanoparticles for Oxygen Reduction
}

Francisco Gonell, Carlos M Sánchez-Sánchez, Vincent Vivier, Christel Laberty-Robert, David Portehault

\section{To cite this version:}

Francisco Gonell, Carlos M Sánchez-Sánchez, Vincent Vivier, Christel Laberty-Robert, David Portehault. Experimental Descriptors for the Synthesis of Multicationic Nickel Perovskite Nanoparticles for Oxygen Reduction. ACS Applied Nano Materials, 2020, 3 (8), pp.7482-7489. 10.1021/acsanm.0c01094 . hal-02912046

\section{HAL Id: hal-02912046 \\ https://hal.sorbonne-universite.fr/hal-02912046}

Submitted on 1 Sep 2020

HAL is a multi-disciplinary open access archive for the deposit and dissemination of scientific research documents, whether they are published or not. The documents may come from teaching and research institutions in France or abroad, or from public or private research centers.
L'archive ouverte pluridisciplinaire HAL, est destinée au dépôt et à la diffusion de documents scientifiques de niveau recherche, publiés ou non, émanant des établissements d'enseignement et de recherche français ou étrangers, des laboratoires publics ou privés. 


\section{Experimental Descriptors for the Synthesis of}

\section{Multicationic Nickel Perovskite Nanoparticles for}

\section{Oxygen Reduction}

Francisco Gonell ${ }^{a}$, Carlos M. Sánchez-Sánchez ${ }^{b}$, Vincent Vivier ${ }^{b}$, Christel Laberty-

Roberta, David Portehaulta, *

a Sorbonne Université, CNRS, Laboratoire de Chimie de la Matière Condensée de Paris

(CMCP), 4 place Jussieu, F-75005, Paris, France

${ }^{b}$ Sorbonne Université, CNRS, Laboratoire Interfaces et Systèmes Electrochimiques

(LISE), 4 place Jussieu, F-75005, Paris, France 
ABSTRACT

In many liquid-phase synthesis methods developed to produce nanomaterials, the key parameters governing the selective synthesis of solids and compounds are clearly identified, e.g. heat treatment profile, precursors solubility, $\mathrm{pH}$, etc. Most of these wellunderstood approaches rely on relatively low temperature processes, below $400{ }^{\circ} \mathrm{C}$, where conventional solvents are still stable. Interestingly, thermally stable inorganic molten salts enable to widen the temperature range for liquid-phase syntheses. They provide access to other families of crystalline solids requiring higher temperatures, as multicationic oxides. Nonetheless, the mechanisms that govern solid state formation and phase selection when different compounds compete are poorly understood. Herein, we report how experimental parameters, such as temperature, time, reaction medium 
composition and solvent oxo-basicity, enable to drive the synthesis mechanisms in molten salts towards nanoscaled multicationic oxides. We especially enlighten the phaseselective synthesis of pseudo-cubic perovskite $\mathrm{LaNiO}_{3}$ and layered Ruddlesden-Popper phases $\mathrm{La}_{2} \mathrm{NiO}_{4}$ and $\mathrm{LaSrNiO}_{4}$ at the nanoscale, by suggesting that the oxidation state of the metallic precursor plays a key role in the reaction pathway. This allows designing electrocatalysts for oxygen reduction reaction.

KEYWORDS. perovskite, layered materials, nickel oxide, oxygen reduction reaction, molten salts, synthesis mechanism. 


\section{INTRODUCTION}

In the last decades, bottom-up nanomaterials synthesis has delivered exciting properties, with a plethora of nanoparticles accessible through solution chemistry, mostly in water or organic solvents. These liquids limit the synthesis temperature up to $350-400{ }^{\circ} \mathrm{C}$. In this temperature range, metallic and ionic solids are easily crystallized. On the opposite, solids bearing a strong covalence character exhibit low crystallinity and even an amorphous character when they are prepared by liquid-phase synthesis. Indeed, such solids require a high temperature to overcome the energy barrier of crystallization, which includes reorganization of directional and strong bonds into the solid. Such high temperatures are energetically costly and trigger large crystal growth, hence inhibiting our ability to synthesize individualized nanoparticles.

This limit can be overcome by performing nanoparticles synthesis in molten salts. ${ }^{1}$ These liquid media are especially suited for high temperature syntheses (generally up to $\left.1000^{\circ} \mathrm{C}\right),,^{1,2}$ because they are thermally stable, exhibit low vapor pressure and provide liquid media for the synthesis of nanoparticles with an increased reaction rate compared 
to solid-state processes. These enhanced kinetics result in a decrease in the grain size.

Molten salts are then ideal to synthesize solids that need harsh conditions to crystallize

through solid-state processes. Other advantages of molten salts encompass their low cost, low environmental impact and easy implementation at the large scale, as shown by their current industrial applications. ${ }^{3}$ Molten salts have delivered materials previously not available at the nanoscale such as some multicationic oxides, ${ }^{4-6}$ borides, ${ }^{7-9}$ carbides, ${ }^{10}$ group VI semiconductors, ${ }^{11}$ etc. Despite numerous examples showing the rich versatility of molten salts for synthesis, reports dealing with reaction mechanisms in these media are scarce. Mechanistic studies would allow better understanding of nanoparticles formation in molten salts, enable selective synthesis of solids, and further provide design rules towards nanomaterials with tuned properties.

The perovskite structure can accommodate various anions and cations and shows a high compositional versatility to address various application fields. ${ }^{12-15}$ This diversity is reflected into related materials such as Ruddlesden-Popper phases (RPs) with stoichiometry $A_{n+1} B_{n} O_{3 n+1}\left(\operatorname{or}(A O)\left(A B O_{3}\right)_{n}, n=1,2 \ldots\right)$. RPs are built on $n A^{\prime} O_{3}$ perovskite 
layers alternating with a AO rock-salt layer. Their transport properties are characteristic of two-dimensional materials. ${ }^{16} \mathrm{AO}$ layers and oxygen non-stoichiometry provide additional oxygen ion transport compared to the cubic perovskite structure. Nickel-based perovskites exhibit structural and compositional versatility, adjustable nickel oxidation state, ionic and/or electronic conductivity that make these materials widely studied for spintronics, ${ }^{17}$ as redox catalysts in $\mathrm{NO}_{\mathrm{x}}$ elimination, ${ }^{18}$ and as electrocatalysts of the oxygen reduction reaction ${ }^{19,20}$ in cathodes of $\mathrm{Li}-\mathrm{O}_{2}$ batteries ${ }^{21,22}$ and solid oxide fuel cells. ${ }^{23-25}$

Nickel-based perovskites have been produced through solid-state synthesis above $1000{ }^{\circ} \mathrm{C}$, yielding large crystals with uncontrolled morphology. ${ }^{20}$ Sol-gel pathways have also been explored to produce materials with smaller crystal size. Yet, the thermal posttreatment required for crystallization hinders size and morphology control, and delivers crystals with large amounts of defects that limit charge transport. Molten salts are then promising media for lowering the synthesis temperature of nickel-based perovskites, to achieve smaller and more crystallized nanoparticles for tuning catalytic properties. 
In this work, we demonstrate that a careful choice of the synthesis media and reaction conditions enables the production of $\mathrm{LaNiO}_{3}, \mathrm{La}_{2} \mathrm{NiO}_{4}$ and $\mathrm{SrLaNiO}_{4}$ nanoparticles through molten salts synthesis (Scheme 1). The synthesis mechanisms are studied to highlight the parameters governing the formation of nanoscaled multicationic oxides with controlled crystal structure. We then show that controlling the adequate synthesis parameters enables to tune the electrocatalytic activity of nickel-based perovskites for the oxygen reduction reaction (ORR) in alkaline solution.

Synthesis descriptors

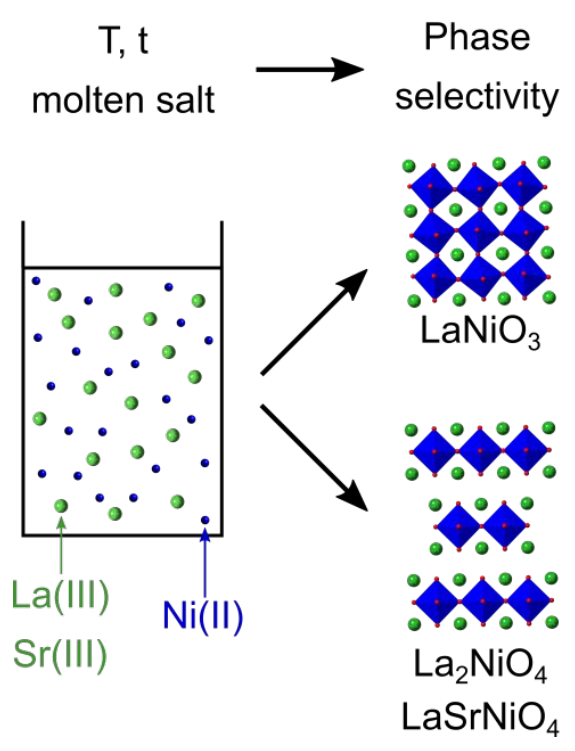

Scheme 1. Schematic representation of selective molten salt syntheses of $\mathrm{Ni}$ perovskites. 


\section{EXPERIMENTAL SECTION}

Synthesis. All reagents were purchased from Sigma-Aldrich, otherwise written, and used as received without further purification. The amounts of precursors used in each synthesis are the following: Pseudo-cubic $\mathrm{LaNiO}_{3}$ synthesis: $6.5 \mathrm{mmol}$ of $\mathrm{Ni}\left(\mathrm{NO}_{3}\right)_{2} \cdot 6 \mathrm{H}_{2} \mathrm{O}, 6.5 \mathrm{mmol}$ of $\mathrm{La}\left(\mathrm{NO}_{3}\right)_{3} \cdot 6 \mathrm{H}_{2} \mathrm{O}$, and $65 \mathrm{mmol}$ of $\mathrm{KNO}_{3}$ or $95 \mathrm{mmol}$ of $\mathrm{NaNO}_{2}$. Layered $\mathrm{La}_{2} \mathrm{NiO}_{4}$ synthesis: $6.5 \mathrm{mmol}$ of $\mathrm{Ni}\left(\mathrm{NO}_{3}\right)_{2} \cdot 6 \mathrm{H}_{2} \mathrm{O}, 13 \mathrm{mmol}$ of $\mathrm{La}\left(\mathrm{NO}_{3}\right)_{3} \cdot 6 \mathrm{H}_{2} \mathrm{O}$, and $65 \mathrm{mmol}$ of $\mathrm{KNO}_{3}$ or $95 \mathrm{mmol}$ of $\mathrm{NaNO}_{2}$. Layered $\mathrm{LaSrNiO}_{4}$ synthesis: $6.5 \mathrm{mmol}$ of $\mathrm{Ni}\left(\mathrm{NO}_{3}\right)_{2} \cdot 6 \mathrm{H}_{2} \mathrm{O}, 6.5 \mathrm{mmol}$ of $\mathrm{La}\left(\mathrm{NO}_{3}\right)_{3} \cdot 6 \mathrm{H}_{2} \mathrm{O}, 6.5 \mathrm{mmol}$ of $\mathrm{Sr}\left(\mathrm{NO}_{3}\right)_{2}$ and $95.2 \mathrm{mmol}$ of $\mathrm{NaNO}_{2}$.

For each synthesis, the reagents were mixed with a few drops of ethanol, milled by using a Retsch MM400 ball miller with $50 \mathrm{~mL}$ stainless steel bowls filled with one ball. The resulting powder was dried under vacuum at $40^{\circ} \mathrm{C}$ overnight. $2.5 \mathrm{~g}$ of each mixture was introduced in an alumina crucible and treated in a preheated oven at the corresponding temperature and time discussed in this work. Then, the reaction was quenched at room temperature by removing the crucible from the oven. The resulting black powder was 
washed by centrifugation with deionized water several times and dried under vacuum at room temperature overnight.

Seeded syntheses were performed to convert previous synthesized particles (seeds) into other perovskites: $\mathrm{LaNiO}_{3}: 0.25 \mathrm{~g}$ of $\mathrm{La}_{2} \mathrm{NiO}_{4}, 0.6 \mathrm{mmol}$ of $\mathrm{Ni}\left(\mathrm{NO}_{3}\right)_{2} \cdot 6 \mathrm{H}_{2} \mathrm{O}$ and $2.5 \mathrm{~g}$ of $\mathrm{NaNO}_{2}$ were milled in an agate mortar and dried overnight at $40^{\circ} \mathrm{C}$ under vacuum. This mixture was introduced in an alumina crucible and treated at several temperatures and times. $\mathrm{La}_{2} \mathrm{NiO}_{4}: 0.25 \mathrm{~g}$ of $\mathrm{LaNiO}_{3}, 0.1 \mathrm{mmol}$ of $\mathrm{La}\left(\mathrm{NO}_{3}\right)_{3} \cdot 6 \mathrm{H}_{2} \mathrm{O}$ and $2.5 \mathrm{~g}$ of $\mathrm{NaNO}_{2}$ were milled in an agate mortar and dried overnight at $40^{\circ} \mathrm{C}$ under vacuum. This mixture was introduced in an alumina crucible and treated at $800^{\circ} \mathrm{C}$ for 0.5 hours. $\mathrm{LaSrNiO}: 0.25 \mathrm{~g}$ of $\mathrm{LaNiO}_{3}$ or $0.41 \mathrm{~g}$ of $\mathrm{La}_{2} \mathrm{NiO}_{4}, 0.1 \mathrm{mmol}$ of $\mathrm{Sr}\left(\mathrm{NO}_{3}\right)_{2}$ and $2.5 \mathrm{~g}$ of $\mathrm{NaNO}_{2}$ were milled in an agate mortar and dried overnight at $40{ }^{\circ} \mathrm{C}$ under vacuum. This mixture was introduced in an alumina crucible and treated at $800^{\circ} \mathrm{C}$. After 1 hour, all reaction media were quenched at room temperature, washed with deionized water several times and dried at room temperature under vacuum overnight. 
Stability tests of the preformed materials in the reaction media, so-called "blank experiments" were performed with $0.25 \mathrm{~g}$ of the previously synthesized material, which was mixed with $2.5 \mathrm{~g}$ of $\mathrm{NaNO}_{2}$ and milled in an agate mortar, then dried overnight at $40{ }^{\circ} \mathrm{C}$ under vacuum. This mixture was introduced in an alumina crucible and treated at the same temperature and time required for obtaining the targeted material (optimal conditions previously studied). Then, the synthesis media was quenched at room temperature and the as-synthesized material was washed with deionized water several times and dried at room temperature under vacuum overnight.

Characterization. Powder X-ray Diffraction (XRD) was performed on a Bruker D8 advance diffractometer equipped with a $\mathrm{Cu} \mathrm{Ka}$ source. High resolution transmission electron microscopy (HRTEM) was carried out on a JEOL JEM2100Plus LaB 6 working at an accelerating voltage of $200 \mathrm{kV}$ and field-emission scanning electron microscopy (SEM) on a Hitachi SU-70 microscope. XRD and electron diffraction patterns were indexed along the 00-033-0711, 00-034-0314, 04-007-0158 references from the PDF-4 database for $\mathrm{LaNiO}_{3}, \mathrm{La}_{2} \mathrm{NiO}_{4}$, $\mathrm{LaSrNiO}$, respectively. The atomic composition was 
measured by inductively coupled plasma optical emission spectrometry (ICP-OES) on a Varian Vista analyzer. The surface area was calculated from the adsorption branch of the $\mathrm{N}_{2}$ sorption isotherm according to the BET method at $77 \mathrm{~K}$ using an ASAP 2010 equipment. Prior to sorption measurements, the powders were degassed at $300{ }^{\circ} \mathrm{C}$ for $4 h$.

The electrocatalytic properties were studied through a three-electrode setup, using a rotating disk electrode (RDE) made of glassy carbon as working electrode, a Pt wire as a counter electrode and an $\mathrm{Ag} / \mathrm{AgCl}$ electrode as reference connected to a VPS Biologic potentiostat. As previously described, ${ }^{26}$ a conductive ink containing the electrocatalyst (10 mg), black carbon $(10 \mathrm{mg})$ and Nafion $(435 \mu \mathrm{L})$ in ethanol $(10 \mathrm{~mL})$ was deposited on the polished glassy carbon $\left(0.07 \mathrm{~cm}^{2}\right)$ of the RDE after sonification for 1 hour and then dried for 1 hour. $10 \mu \mathrm{L}$ were deposited for performing cyclic voltammetry (CV) and lower amounts $(2 \mu \mathrm{L})$ of the ink were used in order to see the catalyst deactivation during chronopotentiometry (current density: $0.5 \mathrm{~mA} \mathrm{~cm}^{-2}$ disk). For comparison with benchmark catalys a ink with $20 \% \mathrm{Pt} / \mathrm{C}$ (Alfa Aesar) was prepared using $12.5 \mathrm{mg}$ of the material and 
the same amounts of EtOH and Nafion-117 as before. $1.5 \mu \mathrm{L}$ of this ink was deposited on the GC electrode for performing the CV. The films were hydrated with one drop of $0.1 \mathrm{M} \mathrm{KOH}$ electrolyte during $30 \mathrm{~min}$ before the experiments. All the measurements were performed in $\mathrm{O}_{2}$-saturated electrolyte at a $10 \mathrm{mV} \mathrm{s}^{-1}$ scan rate and a rotation rate of $1600 \mathrm{rpm}$. Each experiment was repeated 3 times to ensure reproducibility. Especially, the Koutecky-Levich analysis was performed for each sample on three different electrodes. The number of electrons exchanged was evaluated by averaging the two CV branches for each measurement. The numbers of electrons calculated for three different electrodes were then averaged and the different measurements enabled to evaluate the uncertainty at \pm 0.2 for each sample.

\section{RESULTS AND DISCUSSION}

The synthesis of $\mathrm{LaNiO}_{3}$ and $\mathrm{La}_{2} \mathrm{NiO}_{4}$ was performed using metal nitrates ( $\mathrm{La}(\mathrm{III})$ and $\mathrm{Ni}(\mathrm{II}))$ of varying ratios. $\mathrm{KNO}_{3}$ was used as solvent to dissolve metal nitrates and to efficiently supply oxygen for the synthesis of perovskites. ${ }^{4,27}$ The powder $\mathrm{X}$-ray diffraction (XRD) patterns for the $\mathrm{LaNiO}_{3}$ system (Figure S1) indicate that high temperature $\left(800^{\circ} \mathrm{C}\right)$ 
treatments and long reaction times (6 hours) are needed to obtain pure $\mathrm{LaNiO}_{3}$. When the ratio of $\mathrm{La}$ and $\mathrm{Ni}$ reagents is adjusted to target $\mathrm{La}_{2} \mathrm{NiO}_{4}$, even prolonged heating at $800{ }^{\circ} \mathrm{C}$ for $14 \mathrm{~h}$ yields $\mathrm{LaNiO}_{3}$ as the major product with a small amount of $\mathrm{La}_{2} \mathrm{NiO}_{4}$ (Figure S2). The results suggest that in $\mathrm{KNO}_{3}$, the reagents are not sufficiently reactive to yield $\mathrm{LaNiO}_{3}$ below $800{ }^{\circ} \mathrm{C}$ and to form single-phase $\mathrm{La}_{2} \mathrm{NiO}_{4}$. We then investigated a solvent prone to increase the reactivity of the initial metal salts by acting as a better $\mathrm{O}^{2-}$ source.

$\mathrm{NaNO}_{2}$ is a good candidate thanks to its high oxo-basicity. ${ }^{28} \mathrm{NaNO}_{2}$ has been efficiently used as synthesis medium for several systems including $\mathrm{ZrO}_{2},{ }^{28-30} \mathrm{MgO},{ }^{31}$ $\mathrm{La}_{0.5} \mathrm{Sr}_{1.5} \mathrm{MnO}_{4}{ }^{26}$ Indeed, the reactivity of $\mathrm{Ni}(\mathrm{II})$ and $\mathrm{La}(\mathrm{III})$ nitrates drastically increases in $\mathrm{NaNO}_{2}$ (Figure 1a). $\mathrm{NaNO}_{2}$ yields a mixture of $\mathrm{LaNiO}_{3}$ and $\mathrm{La}_{2} \mathrm{NiO}_{4}$ at $600{ }^{\circ} \mathrm{C}$ (Figure 1a), while $\mathrm{LaNiO}_{3}$ could not be detected in $\mathrm{KNO}_{3}$ in similar conditions (Figure S1). The proportion of $\mathrm{LaNiO}_{3}$ increases with the reaction time, as shown by the increased relative intensity of the corresponding XRD peaks. Minor amounts of $\mathrm{NiO}$ are also detected at $600{ }^{\circ} \mathrm{C}$ (Figure 1a). The crystal size calculated from $\mathrm{XRD}$ for $\mathrm{LaNiO}_{3}$ obtained at 
$600{ }^{\circ} \mathrm{C} / 8 \mathrm{~h}$ is $33 \mathrm{~nm}$ and the surface area is $9 \mathrm{~m}^{2} \mathrm{~g}^{-1}$ according to $\mathrm{N}_{2}$ sorption. Inductively coupled plasma (ICP) analysis confirmed the expected La:Ni ratio 1:1.

Scanning (SEM) and transmission (TEM) electron microscopies show that $\mathrm{LaNiO}_{3}$ is composed of well faceted truncated cubes with an average size of $100 \mathrm{~nm}$ (Figure 1b-d).

Smaller $20 \mathrm{~nm}$ particles are also visible in these images. Energy dispersive X-ray (EDX) analysis indicates only the presence of $\mathrm{Ni}$ and $\mathrm{O}$ in these particles, in agreement with high resolution TEM (HRTEM, Figure S3) indicating the NiO structure, as powder XRD (Figure 1a). Focusing on the $100 \mathrm{~nm}$ particles (Figure 1e), the selected area electron diffraction (SAED) pattern can be indexed over $\mathrm{LaNiO}_{3}$ structure. Interestingly, seemingly aggregated particles show a single crystal-like pattern, indicating highly oriented crystals.

Figure $1 f$ shows a HRTEM micrograph of a particle 

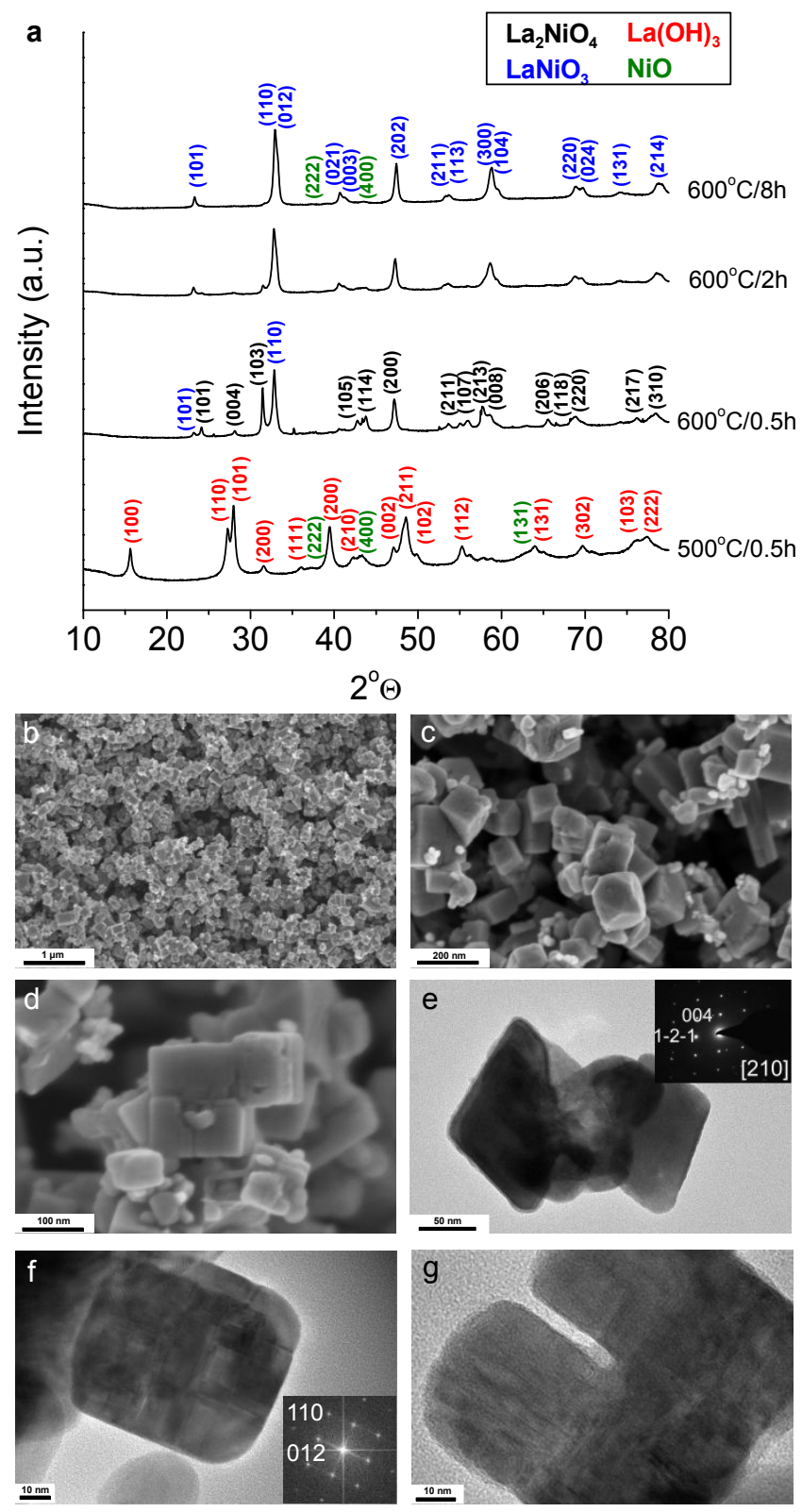
pattern of the particles ensemble. (f, g) HRTEM image (inset shows the corresponding FFT). The SAED and FFT are indexed along the $\mathrm{LaNiO}_{3}$ structure.

of $80 \mathrm{~nm}$ diameter, which can again be fully indexed on the $\mathrm{LaNiO}_{3}$ structure. The material is then composed of a majority of $\sim 100 \mathrm{~nm} \mathrm{LaNiO}$ 3 cubes with small amounts of $20 \mathrm{~nm}$ $\mathrm{NiO}$ particles. The $\mathrm{LaNiO}_{3}$ particle size measured by electron microscopy is larger than the one calculated by XRD. This discrepancy might originate from the $\sim 100 \mathrm{~nm}$ particles (Figure $1 \mathrm{~d}$ and $1 \mathrm{~g}$ ) being formed by aggregation of smaller cubic particles. $\sim 30 \mathrm{~nm}$ cubic particles are indeed perfectly oriented in respect to each other within large cubes. The defects at the grain boundaries may limit the lattice coherence, yielding small XRD crystal size, even if the primary grains are iso-oriented as shown by SAED and HRTEM.

When the La:Ni ratio is increased in order to obtain the RP phase $\mathrm{La}_{2} \mathrm{NiO}_{4}$, the behavior of the reaction medium changes completely. At $600^{\circ} \mathrm{C}$, the product is a mixture of $\mathrm{La}(\mathrm{OH})_{3}$ and $\mathrm{La}_{2} \mathrm{NiO}_{4}$ (Figure 2a). The content of the RP phase increases with the temperature up to $800^{\circ} \mathrm{C}$. When the reaction time is increased from $0.5 \mathrm{~h}$ to $2 \mathrm{~h}$, the layered phase disappears at the benefit of hydroxides. Then, in the optimal 
temperature/time conditions $\left(800^{\circ} \mathrm{C} / 0.5 \mathrm{~h}\right)$, the La:Ni ratio was adjusted by decreasing the La concentration and keeping constant the $\mathrm{Ni}$ content, in order to avoid the formation of $\mathrm{La}(\mathrm{OH})_{3}$ impurity. For the nominal ratio $\mathrm{La}: \mathrm{Ni}=1.8: 1$, the $\mathrm{La}(\mathrm{OH})_{3}$ content is minimized (Figure S4). The material then consists in $\mathrm{La}_{2} \mathrm{NiO}_{4}$ with minor amounts of lanthanum hydroxide. The $\mathrm{La}_{2} \mathrm{NiO}_{4}$ crystal size calculated from XRD patterns is $76 \mathrm{~nm}$ and the surface area evaluated by $\mathrm{N}_{2}$ adsorption is $9 \mathrm{~m}^{2} \mathrm{~g}^{-1}$. The composition evaluated by ICP analysis matches $\mathrm{La}_{2} \mathrm{NiO}_{4}$. SEM and TEM indicate that $\mathrm{La}_{2} \mathrm{NiO}_{4}$ is composed of faceted $60 \mathrm{~nm}$ nanoparticles (Figure $\mathbf{2 b}-\mathbf{e}$ ), in agreement with the Scherrer crystallite size. SAED shows that the material is composed by single crystal nanoparticles randomly oriented (Figure 2c). Some grain boundaries can also be observed, showing iso-oriented crystals (Figure 2d and e). 

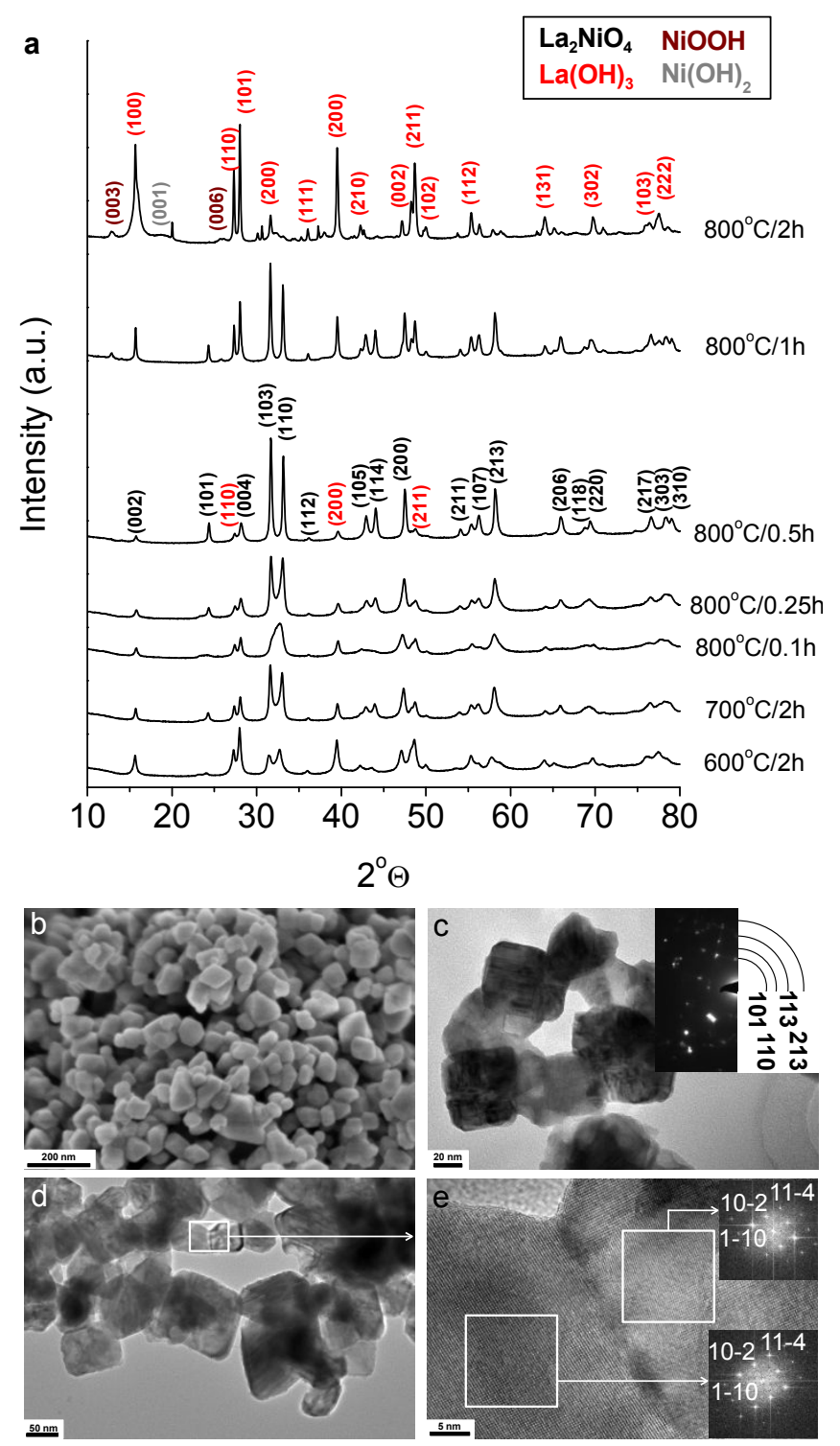

Figure 2. (a) XRD diagrams of the powders obtained at different temperatures and reaction times when targeting $\mathrm{La}_{2} \mathrm{NiO}_{4}$ in $\mathrm{NaNO}_{2}$. Electron microscopy images of $\mathrm{La}_{2} \mathrm{NiO}_{4}$ $\left(800^{\circ} \mathrm{C} / 0.5 \mathrm{~h}\right.$ ) (b) SEM and (c and d) low magnification TEM images (inset in c shows the corresponding SAED pattern indexed along the $\mathrm{La}_{2} \mathrm{NiO}_{4}$ structure). (e) HRTEM image 
(insets shows the corresponding FFTs of each area in the squares. They are indexed along the $\mathrm{La}_{2} \mathrm{NiO}_{4}$ structure).

Compared to $\mathrm{KNO}_{3}$, the use of $\mathrm{NaNO}_{2}$ as solvent enables a $200{ }^{\circ} \mathrm{C}$ decrease of the reaction temperature for obtaining the pseudo-cubic perovskite. On the other side, the selectivity towards the layered perovskite structure drastically increases, so that the pseudo-cubic phase could not be detected in the whole synthesis temperature range. The higher Lux-Flood basicity that $\mathrm{NO}_{2}^{-}$shows compared to $\mathrm{NO}_{3}^{-}$indicates its larger propensity to deliver $\mathrm{O}^{2-}$ in the synthesis media. ${ }^{28}$ Indeed the dissociation constant to oxide anions is $10^{10}$ higher for nitrites than for nitrates. ${ }^{28}$ The increase in the $\mathrm{O}^{2-}$ concentration, namely the oxo-basicity, may equalize cations reactivity, as it is reported in aqueous media with Brønsted basicity at high $\mathrm{pH} .{ }^{32}$ Such a behavior is also well documented in non-hydrolytic sol-gel synthesis of titanate perovskites, ${ }^{33}$ which results from the reactivity of the different cations being very similar in e.g. benzylic alcool. ${ }^{33}$ Hence, the increase in oxo-basicity should result in the common incorporation of different cations in the same compound. The higher oxo-basicity of molten nitrites also drives 


\begin{abstract}
phase selectivity to oxygen-rich solids, hence favoring the RP phase versus the pseudocubic perovskite.
\end{abstract}

The high versatility of molten salt syntheses allowed expanding the range of layered perovskites by replacing lanthanum with strontium. Figure $3 a$ shows the evolution of the crystalline structure as a function of the synthesis temperature and time towards $\mathrm{LaSrNiO}_{4}$. At $600{ }^{\circ} \mathrm{C}$, the $\mathrm{XRD}$ peaks can be assigned to $\mathrm{La}_{2} \mathrm{NiO}_{4}$, which is confirmed by EDX that does not detects Sr. By increasing the temperature, Sr could be incorporated in the material $\left(\mathrm{La}_{2} \mathrm{NiO}_{4}\right.$ and $\mathrm{Sr}_{4} \mathrm{Ni}_{3} \mathrm{O}_{9}$ at $\left.700{ }^{\circ} \mathrm{C}\right)$. At $800^{\circ} \mathrm{C}$ and $0.5 \mathrm{~h}$, the peaks corresponding to (103) and (110) planes of the layered perovskite structure show a shoulder, which indicates the presence of $\mathrm{La}_{2} \mathrm{NiO}_{4}$ and $\mathrm{LaSrNiO}_{4}$. After $1 \mathrm{~h}$ at $800{ }^{\circ} \mathrm{C}$, $\mathrm{La}_{2} \mathrm{NiO}_{4}$ disappears and $\mathrm{LaSrNiO}_{4}$ remains the major product. The XRD crystal size of $\mathrm{LaSrNiO}_{4}$ is $49 \mathrm{~nm}$, with a BET surface area of $13 \mathrm{~m}^{2} \mathrm{~g}^{-1}$ and a well faceted 

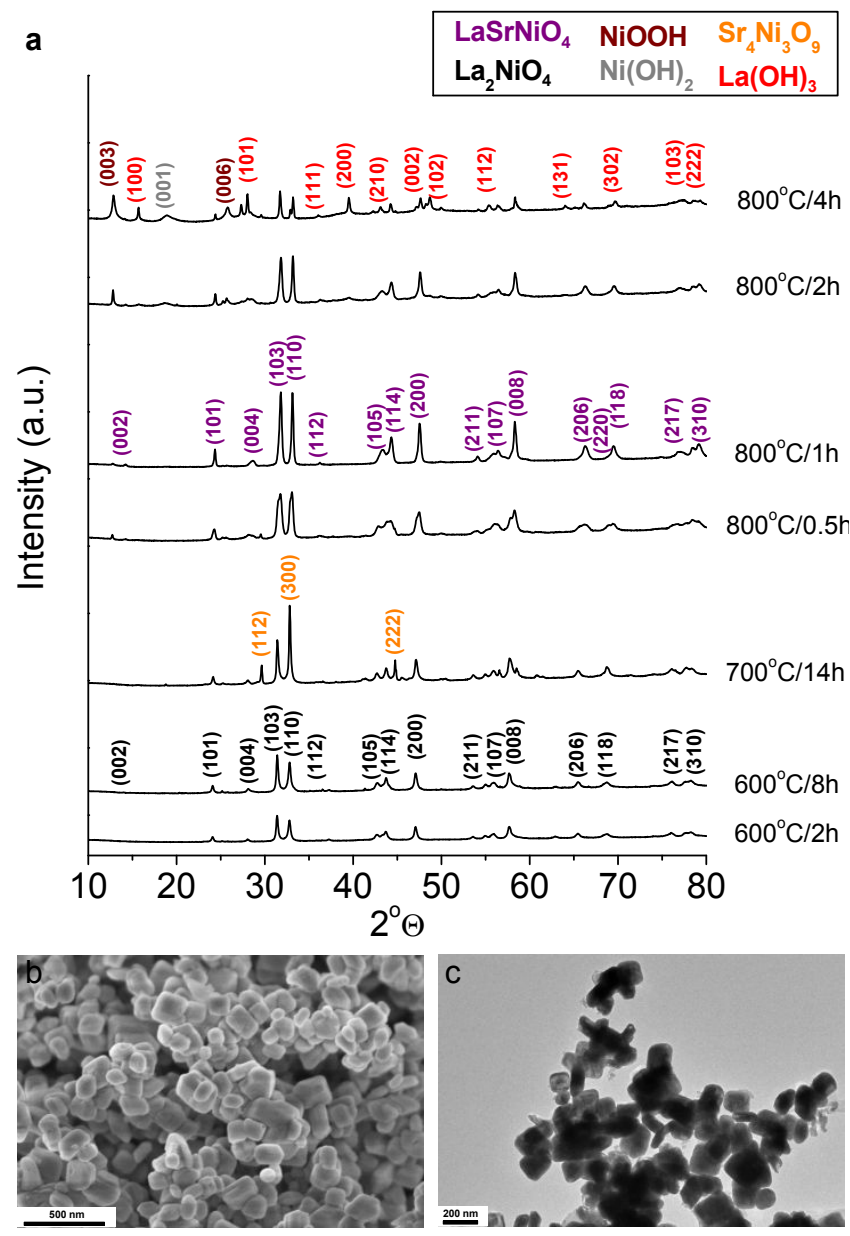

Figure 3. (a) XRD diagrams of the powders obtained at different temperatures and reaction times when targeting $\mathrm{LaSrNiO}_{4}$ in $\mathrm{NaNO}_{2}$. (b) SEM and (c) TEM micrographs of $\mathrm{LaSrNiO}_{4}$ obtained at $800{ }^{\circ} \mathrm{C} / 1 \mathrm{~h}$.

morphology of platelets of $100-200 \mathrm{~nm}$ basal face and $50 \mathrm{~nm}$ thickness (Figure $3 \mathrm{~b}$ and c). If the synthesis time is prolonged beyond $1 \mathrm{~h}$, the XRD peaks of the layered compound disappear, showing that the RP phase decomposes. The final product obtained after 
washing is composed of several single cation hydroxides. No significant change in the XRD patterns (Figure S5), morphology (Figure S6a and b) and composition (Table S1) was observed when the content of strontium in the reaction medium was increased. When no strontium was introduced, the product was a mixture of different single cation (oxy)hydroxides. This observation highlights the importance of strontium to stabilize the Ruddlesden-Popper structure, in good agreement with the decomposition of $\mathrm{La}_{2} \mathrm{NiO}_{4}$ at $800{ }^{\circ} \mathrm{C} / 1 \mathrm{~h}$ (Figure 3a). A slight shift of (103) and (110) planes towards lower angles is observed when the Sr content decreases, in agreement with the decreasing amount of strontium in the materials (Table S1) and the expected increase of the lattice parameters in relation with the ionic radii of $\mathrm{La}(\mathrm{III})(1.15 \AA)$ and $\operatorname{Sr}(\mathrm{II})(1.13 \AA)$. The material with the lowest strontium content (La:Ni:Sr 1:1:0.2) shows particle a size around $70 \mathrm{~nm}$ very similar that the one when targeting $\mathrm{La}_{2} \mathrm{NiO}_{4}$ (Figure S6c and d).

A common feature is observed for the pathways of crystallization in all the syntheses reported above. In the two systems $\mathrm{LaNiO}_{3}$ and $\mathrm{LaSrNiO}_{4}$, low temperatures and short reaction times result $\mathrm{La}_{2} \mathrm{NiO}_{4}$ as an intermediate product. Such behavior can be explained 
on the basis of nickel oxidation state (OS). The nickel precursor used in the synthesis is nickel(II) species, as in the intermediate phase $\mathrm{La}_{2} \mathrm{NiO}_{4}$. Hence, the two different reaction media evolve through a first step involving no redox processes, but only the basicity of the solvent: the first step consists in the evolution through constant oxidation state $\mathrm{Ni}(\mathrm{II})$. Then, in a second step, nickel appears to be oxidized to $\mathrm{Ni}(\mathrm{III})$ and yield $\mathrm{LaNiO}_{3}$ and $\mathrm{LaSrNiO}_{4}$, depending on the medium composition. Hence, we suggest that the nickel oxidation state drives phase selectivity during the synthesis (Scheme 1).

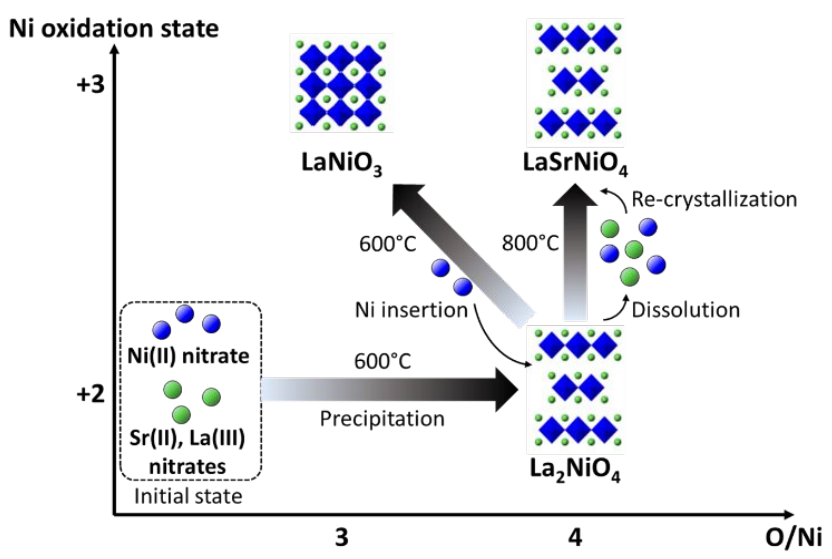

Scheme 2. Proposed mechanisms involved in the synthesis of nickel-based perovskites.

If the nickel oxidation state drives the crystallization pathways of nickel-based perovskites in $\mathrm{NaNO}_{2}$, the mechanisms of transformation from the intermediate phase $\mathrm{La}_{2} \mathrm{NiO}_{4}$ to the 
final compounds in molten $\mathrm{NaNO}_{2}$ require further discussion. In order to shed light on this aspect, syntheses have been performed by using preformed perovskite particles in the presence (seeded synthesis) and in the absence (blank synthesis) of the metal salt precursor required to reach the adequate stoichiometry in the final product.

Treating $\mathrm{La}_{2} \mathrm{NiO}_{4}$ in molten $\mathrm{NaNO}_{2}$ without metal salt, the structure is stable in that solvent at $600{ }^{\circ} \mathrm{C}$ for $8 \mathrm{~h}$, the conditions of formation of $\mathrm{LaNiO}_{3}$ (Figures 1 and $\mathrm{SI}$ 7a). The particle size however increases to $100 \mathrm{~nm}$ (Figure S8), which is probably caused by severe heattreatment conditions. When the stoichiometric amount of $\mathrm{Ni}\left(\mathrm{NO}_{3}\right)_{2} \cdot 6 \mathrm{H}_{2} \mathrm{O}$ is introduced in order to reach $\mathrm{LaNiO}_{3}$, the phase evolution observed (Figure S7b and c) is similar to the direct synthesis of $\mathrm{LaNiO}_{3}$ from the metal salts. When the temperature of synthesis is raised to $800^{\circ} \mathrm{C}$, the perovskite structure decomposes, yielding (oxy)hydroxides (Figure S7d). These species are observed after washing the $\mathrm{NaNO}_{2}$ salt with water. They most probably indicate dissolution of the perovskite into molten $\mathrm{NaNO}_{2} \cdot{ }^{34} \mathrm{TEM}$ micrographs (Figure S9, S10 and S11) of the intermediate sample formed from the $\mathrm{La}_{2} \mathrm{NiO}_{4}$ seeds $\left(600{ }^{\circ} \mathrm{C} / 1 \mathrm{~h}\right)$ show particles of $100-200 \mathrm{~nm}$ surrounded by nanoparticles of $50 \mathrm{~nm}$, and 
smaller nanoparticles of $5 \mathrm{~nm}$. The elemental distribution of this intermediate state was

mapped by Scanning TEM coupled to Energy Dispersive X-ray Spectroscopy

(STEM-EDS, Figures S10 and S11). The 100-200 nm and $50 \mathrm{~nm}$ cubes are composed

by $\mathrm{La}, \mathrm{Ni}$ and $\mathrm{O}$ homogeneously distributed, while smaller $5 \mathrm{~nm}$ particles are made of $\mathrm{Ni}$

and O. HRTEM (Figure S12) shows that the crystal lattice of the $100-200 \mathrm{~nm}$ cubic particles corresponds to the $\mathrm{LaNiO}_{3}$ structure, in agreement with the colocation of $\mathrm{La}, \mathrm{Ni}$ and $\mathrm{O}$. The $50 \mathrm{~nm}$ particles show lattice fringes in agreement with the $\mathrm{La}_{2} \mathrm{NiO}_{4}$ structure (Figure S13), while the $\sim 5 \mathrm{~nm}$ particles at the surface of the larger ones are amorphous and composed by Ni and O. Finally, the sample obtained after $8 \mathrm{~h}$ at $600^{\circ} \mathrm{C}$ (Figure S14) shows the same $100 \mathrm{~nm}$ well faceted cubic morphology as in the original synthesis from the $\mathrm{La}(\mathrm{III})$ and $\mathrm{Ni}(\mathrm{II})$ salts.

The stability of $\mathrm{La}_{2} \mathrm{NiO}_{4}$ particles in molten $\mathrm{NaNO}_{2}$ in the conditions of formation of $\mathrm{LaNiO}_{3}$ (temperature, time), and their morphological, structural and compositional evolution when reacted with nickel (II) nitrate suggest that the formation of $\mathrm{LaNiO}_{3}$ goes through insertion of the dissolved nickel(II) species into the layered $\mathrm{RP} \mathrm{La}_{2} \mathrm{NiO}_{4}$ structure (Scheme 1). This 
cation insertion may occur through a topochemical transformation, as observed for several layered perovskites. ${ }^{5} \mathrm{~A}$ hint of such a reaction mechanism may be found in the persistence of the morphology of the $\mathrm{La}_{2} \mathrm{NiO}_{4}$ particles in the final product. In the present case, the $\mathrm{LaNiO}_{3}$ product from the seeded synthesis is obtained as particles of c.a. 100 nm. During the transformation, one can distinguish smaller building blocks (Figure S12) also observed in the direct synthesis from the metal salts (Figure 1g). These blocks may be originally the ca. $50 \mathrm{~nm} \mathrm{La} \mathrm{NiO}_{4}$ nanoparticles that have reacted and coalesced.

Blank and seeded syntheses from $\mathrm{LaNiO}_{3}$ and $\mathrm{La}_{2} \mathrm{NiO}_{4}$ particles in the same conditions of synthesis of $\mathrm{La}_{2} \mathrm{NiO}_{4}$ and $\mathrm{LaSrNiO}_{4}$, respectively, yield mixtures of (oxy)hydroxides after washing (Figure S15 and S16). Therefore, the precursor particles were decomposed and the cations were dissolved in the reaction medium. This observation suggests that the synthesis goes through a dissolution-reprecipitation mechanism (Scheme 1). ${ }^{32}$ The difference in the synthesis mechanism toward $\mathrm{LaNiO}_{3}$ on one side, $\mathrm{La}_{2} \mathrm{NiO}_{4}$ and $\mathrm{LaSrNiO}_{4}$ on the other side, going through topochemical transformation and dissolutionreprecipitation, respectively, can be explained in terms of synthesis temperatures. Indeed, 
it is possible to hypothesize that at $600{ }^{\circ} \mathrm{C}$, the temperature may not be sufficient to trigger dissolution of intermediate $\mathrm{La}_{2} \mathrm{NiO}_{4}$, so that its transformation to pseudo-cubic $\mathrm{LaNiO}_{3}$ occurs within the $\mathrm{La}_{2} \mathrm{NiO}_{4}$ particles. At higher temperature, $800{ }^{\circ} \mathrm{C}$, the dissolution of intermediate phases is increased and enables crystallization by dissolution followed by re-precipitation (Scheme 1).

The diversity of nanostructured ligand-free nickel-based perovskites, with lack of defects, obtained through molten salts synthesis provides a unique opportunity to study the influence of the crystal structure of perovskite-related oxides in the oxygen reduction reaction (ORR). In order to study these properties, a conductive ink was prepared with each catalyst and deposited on a rotating disk electrode (RDE), as described in the experimental section. The cyclic voltammograms (CVs) were recorded using a three electrode setup, at a rotating speed of $1600 \mathrm{rpm}$, in $\mathrm{O}_{2}$ saturated $0.1 \mathrm{M} \mathrm{KOH}$. Note that the possible impurities detected by XRD (lanthanum hydroxide, nickel oxide) are not active $^{35}$ in ORR so that the electrocatalytic activities measured originate from the perovskite materials. 

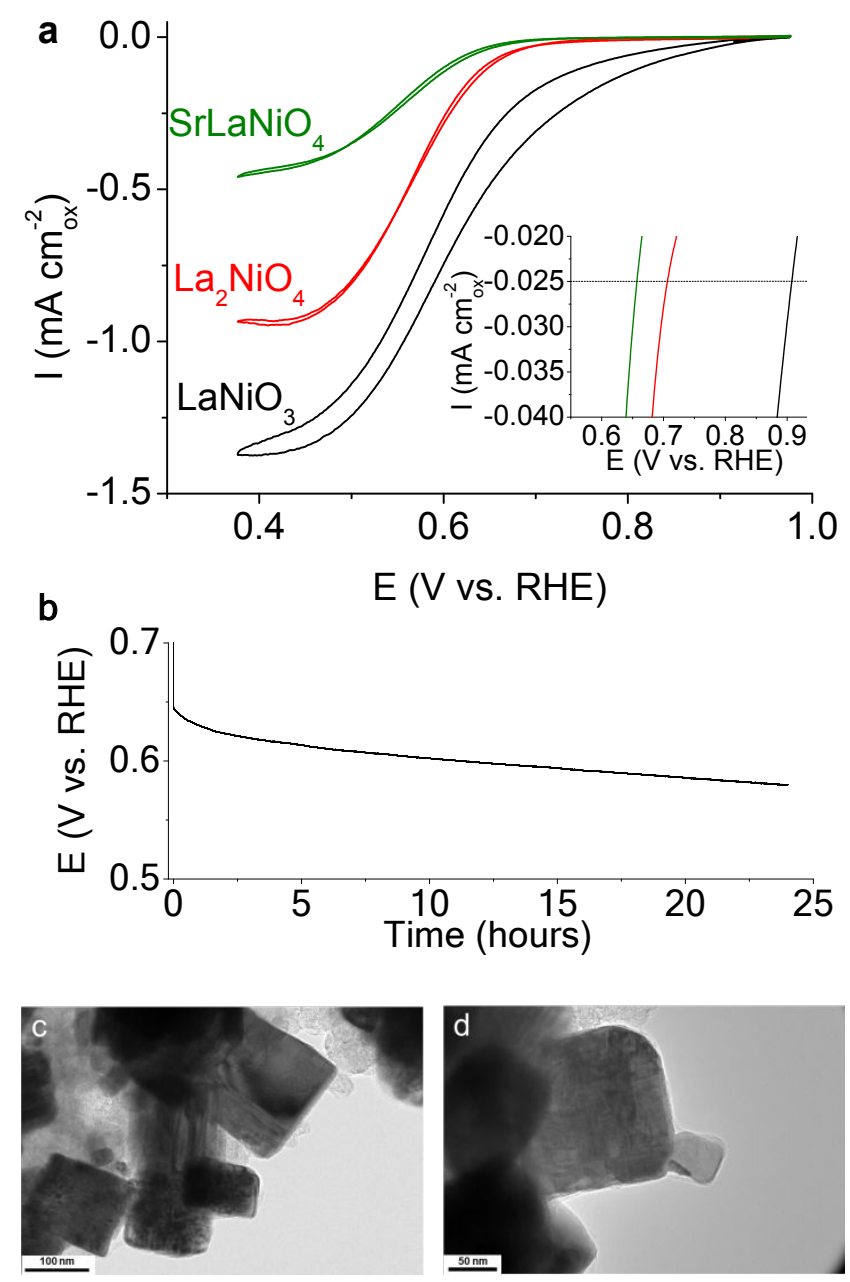

Figure 4. (a) Cyclic voltammograms in ORR conditions (oxide surface-normalized specific activity, $\mathrm{O}_{2}$-saturated $0.1 \mathrm{M} \mathrm{KOH}$ electrolyte) of (a) $\mathrm{LaNiO}_{3}, \mathrm{La}_{2} \mathrm{NiO}_{4}$ and $\mathrm{SrLaNiO}_{4}$ at $1600 \mathrm{rpm}$. The inset shows a zoom of the onset region. (b) Chronopotentiometry curve of $\mathrm{LaNiO}_{3}$ at $0.5 \mathrm{~mA} \mathrm{~cm}$-2 disk, (c and d) TEM images of $\mathrm{LaNiO}_{3}$ after chronopotentiometry. The light contrast particles of $50 \mathrm{~nm}$ in (c) are carbon black particles used as conductive additive. 
The oxide surface area-normalized cyclic voltammograms (CVs) (Figure 4a, Figure S17) show that $\mathrm{LaNiO}_{3}$ is the most active material followed by $\mathrm{La}_{2} \mathrm{NiO}_{4}$ and $\mathrm{SrLaNiO}_{4}$ with a potential at $25 \mu \mathrm{A} \mathrm{cm}^{-2}$ ox of $0.91,0.71$ and $0.66 \mathrm{~V} / \mathrm{RHE}$, respectively. Tafel slopes (Figure S18) are 56, 208 and $152 \mathrm{mV} \cdot \mathrm{dec}^{-1}$ for $\mathrm{LaNiO}_{3}, \mathrm{La}_{2} \mathrm{NiO}_{4}$ and $\mathrm{LaSrNiO}_{4}$ respectively, in good agreement with previous works ${ }^{36}$ and with the overpotentials described above, where the most active materials show lower slopes. The values obtained for $\mathrm{LaNiO}_{3}$ are in agreement with the values previously reported on bulk materials, ${ }^{19,37}$ thus highlighting the high crystallinity of the nanoparticles. Noteworthy, crystallization and significant electrocatalytic activity are triggered by syntheses in molten salts at lower temperature than by using sol-gel and solid-state derived methodologies. $\mathrm{LaNiO}_{3}$ shows a half-wave potential of $0.61 \mathrm{~V}$ vs $\mathrm{RHE}$. This value is lower than for the benchmark Pt/C electrocatalyst (Figure S19) but is comparable to other active perovskites. ${ }^{38}$ As other perovskite electrocatalysts, the nickelates reported herein have the advantage of not containing any precious metal. 
The order of activity $\mathrm{LaNiO}_{3}>\mathrm{La}_{2} \mathrm{NiO}_{4}>\mathrm{SrLaNiO}_{4}$ can be explained by the filling of the Ni 3d orbitals. ${ }^{19}$ According to Shao- Horn et al. ${ }^{19}$ perovskites bearing B-site transition metals with configurations $d^{4}$ or $d^{7}$ show the highest ORR activity because $e_{g}$ degenerated orbitals hold one electron for optimal $\mathrm{O}_{2}$ adsorption. ${ }^{19}$ The $\mathrm{d}^{7}$ configuration of nickel in $\mathrm{LaNi}^{\prime \prime} \mathrm{O}_{3}$ then explains its highest activity. On the contrary, $\mathrm{La}_{2} \mathrm{NiO}_{4}$ exhibits a $\mathrm{d}^{8}$ configuration with lower activity. SrLaNill' $\mathrm{O}_{4}$ seems to deviate from the $\mathrm{d}^{4} / \mathrm{d}^{7}$ rule as it shows the lowest activity despite a $\mathrm{d}^{7}$ configuration. Surface termination with $\mathrm{Sr}^{2+}$ and $\mathrm{La}^{3+}$ cations instead of catalytically active nickel may explain this discrepancy. The number of electrons involved in the ORR according to the Koutecky-Levich analysis (Figures S20, S21 and S22) is 3.5, 3.4 and $3.0( \pm 0.2)$ electrons per $\mathrm{O}_{2}$ for $\mathrm{LaNiO}_{3}$, $\mathrm{La}_{2} \mathrm{NiO}_{4}$ and $\mathrm{SrLaNiO}_{4}$ respectively, suggesting a mixture of 4- and 2- electron mechanisms. The stability of $\mathrm{LaNiO}_{3}$ during ORR was studied with chronopotentiometry (Figure $4 b$ ), showing only a slight deactivation during 24 hours operation. The potential required for reaching a current density of $0.5 \mathrm{~mA} \mathrm{~cm}^{-2}$ disk evolves from -0.65 to $0.58 \mathrm{~V} / \mathrm{RHE}$. This is reflected in the downward shift of the CVs from the initial state to the final state (Figure S23). This slight decay may arise from the partial reduction of $\mathrm{Ni}(\mathrm{III})$ to 
less active $\mathrm{Ni}(\mathrm{II})$ under the reductive conditions applied during the stability test. HRTEM

(Figure 4c-d) shows no significant change of the well faceted cubic morphology after chronopotentiometry. In addition, STEM-EDS mapping for $\mathrm{LaNiO}_{3}$ after chronopotentiometry shows homogeneous $\mathrm{Ni}$ and La distribution (Figure S24), while the atomic composition remains constant, according to EDS analysis. These data further support the stability of the $\mathrm{LaNiO}_{3}$ particles under operation thanks to their high crystallinity.

\section{CONCLUSION}

In this work an accurate choice of the synthetic conditions (temperature, time and solvent oxo-basicity) in molten salts led to the selective synthesis of $\mathrm{LaNiO}_{3}, \mathrm{La}_{2} \mathrm{NiO}_{4}$ and $\mathrm{LaSrNiO}_{4}$ as new nanomaterials that are active electrocatalysts of the oxygen reduction reaction in alkaline media. Reaction intermediates were identified to shed light on the key parameters controlling the formation of nickel-based perovskites in molten salts. Nickel oxidation state governs the perovskite formation, through a common low oxidation state 


\begin{abstract}
$\mathrm{Ni}(\mathrm{II})$ intermediate $\left(\mathrm{La}_{2} \mathrm{NiO}_{4}\right)$ formed from a $\mathrm{Ni}(\mathrm{II})$ salt precursor. The intermediate $\mathrm{La}_{2} \mathrm{NiO}_{4}$
phase then evolves to structures with higher $\mathrm{Ni}$ oxidation state depending on the composition of the reaction medium and on the temperature. Low temperatures $\left(600^{\circ} \mathrm{C}\right)$
\end{abstract}

favor a topochemical transformation where nickel species in solution are inserted into the reaction intermediate $\mathrm{La}_{2} \mathrm{NiO}_{4}$. At higher temperature, the energy input is high enough to trigger dissolution of the precursors promoting a dissolution-reprecipitation pathway.

These results highlight experimental descriptors that govern the formation of nanoparticles of multicationic oxides in molten salts media. We suggest that the oxidation state of the precursor determines the nature of the reaction intermediate, whose further evolution is driven by the composition of the medium and the temperature. These reaction rules should enable further design of synthesis protocols towards multicationic oxides at nanoscale and electrocatalysts for the oxygen reduction reaction and the oxygen evolution reaction.

\title{
ASSOCIATED CONTENT
}




\title{
Supporting Information.
}

The Supporting Information is available free of charge at

https://pubs.acs.org/doi/xxxxxxxxxxxxx

Additional XRD, TEM, electrocataytic and ICP characterization (PDF).

\author{
AUTHOR INFORMATION \\ Corresponding Author \\ *E-mail: david.portehault@sorbonne-universite.fr
}

\section{Funding Sources}

The whole research program received financial support from Region lle-de-France in

the framework of the Domaine d'Intérêt Majeur DIM Nano-K and from the French

national agency for research (ANR) with the project SALTYSPIN ANR-17-CE09-0005.

DP and FG also acknowledge support from the Fondation Collège de France.

\section{Notes}


The authors declare no competing financial interest.

\section{REFERENCES}

(1) Liu, X.; Fechler, N.; Antonietti, M. Salt Melt Synthesis of Ceramics, Semiconductors and Carbon Nanostructures. Chem. Soc. Rev. 2013, 42 (21), 8237-8265. https://doi.org/10.1039/c3cs60159e.

(2) Portehault, D.; Delacroix, S.; Gouget, G.; Grosjean, R.; Chan-Chang, T.-H.-C. Beyond the Compositional Threshold of Nanoparticle-Based Materials. Acc. Chem. Res. 2018, 51, 930-939. https://doi.org/10.1021/acs.accounts.7b00429.

(3) Carenco, S.; Portehault, D.; Boissière, C.; Mézailles, N.; Sanchez, C. Nanoscaled Metal Borides and Phosphides: Recent Developments and Perspectives. Chem. Rev. 2013, 113, 7981-8065. https://doi.org/10.1021/cr400020d.

(4) Thi N'Goc, H. Le; Mouafo, L. D. N.; Etrillard, C.; Torres-Pardo, A.; Dayen, J.-F.; Rano, S.; Rousse, G.; Laberty-Robert, C.; Calbet, J. G.; Drillon, M.; et al. SurfaceDriven Magnetotransport in Perovskite Nanocrystals. Adv. Mater. 2017, 29, 
1604745. https://doi.org/10.1002/adma.201604745.

(5) Li, L.; Deng, J.; Chen, J.; Xing, X. Topochemical Molten Salt Synthesis for Functional Perovskite Compounds. Chem. Sci. 2016, 7 (2), 855-865. https://doi.org/10.1039/c5sc03521j.

(6) Liu, H.; Hu, C.; Wang, Z. L. Composite-Hydroxide-Mediated Approach for the Synthesis of Nanostructures of Complex Functional-Oxides. Nano Lett. 2006, 6(7), 1535-1540. https://doi.org/10.1021/nl061253e.

(7) Portehault, D.; Devi, S.; Beaunier, P.; Gervais, C.; Giordano, C.; Sanchez, C.; Antonietti, M. A General Solution Route toward Metal Boride Nanocrystals. Angew. Chem. Int. Ed. 2011, 50(14), 3262-3265. https://doi.org/10.1002/anie.201006810.

(8) Gouget, G.; Beaunier, P.; Portehault, D.; Sanchez, C. New Route toward Nanosized Crystalline Metal Borides with Tunable Stoichiometry and Variable Morphologies. Faraday Discuss. 2016, 191, 511-525.

(9) Gouget, G.; Debecker, D. P.; Kim, A.; Olivieri, G.; Gallet, J.-J.; Bournel, F.; Thomas, C.; Ersen, O.; Moldovan, S.; Sanchez, C.; et al. In Situ Solid-Gas Reactivity of Nanoscaled Metal Borides from Molten Salt Synthesis. Inorg. Chem. 2017, 56, 


\section{5-9234.}

(10) Liu, X.; Antonietti, M.; Giordano, C. Manipulation of Phase and Microstructure at Nanoscale for SiC in Molten Salt Synthesis. Chem. Mater. 2013, 25 (10), 20212027. https://doi.org/10.1021/cm303727g.

(11) Liu, X.; Giordano, C.; Antonietti, M. A Molten-Salt Route for Synthesis of Si and Ge Nanoparticles: Chemical Reduction of Oxides by Electrons Solvated in Salt Melt. J. Mater. Chem. 2012, 22(12), 5454. https://doi.org/10.1039/c2jm15453f.

(12) Konstantakou, M.; Stergiopoulos, T. A Critical Review on Tin Halide Perovskite Solar Cells. J. Mater. Chem. A 2017, 5 (23), 11518-11549. https://doi.org/10.1039/C7TA00929A.

(13) Hashim, S. S.; Somalu, M. R.; Loh, K. S.; Liu, S.; Zhou, W.; Sunarso, J. PerovskiteBased Proton Conducting Membranes for Hydrogen Separation: A Review. Int. J. Hydrogen Energy 2018, $43 \quad$ (32), 15281-15305. https://doi.org/10.1016/j.ijhydene.2018.06.045.

(14) Sunarso, J.; Hashim, S. S.; Zhu, N.; Zhou, W. Perovskite Oxides Applications in High Temperature Oxygen Separation, Solid Oxide Fuel Cell and Membrane 
Reactor: A Review. Prog. Energy Combust. Sci. 2017, 61, 57-77. https://doi.org/10.1016/j.pecs.2017.03.003.

(15) Ansari, M. I. H.; Qurashi, A.; Nazeeruddin, M. K. Frontiers, Opportunities, and Challenges in Perovskite Solar Cells: A Critical Review. J. Photochem. Photobiol. C Photochem. Rev. 2018, 35, 1-24. https://doi.org/10.1016/j.jphotochemrev.2017.11.002.

(16) Lobanov, M. V.; Li, S.; Greenblatt, M. Structural, Magnetic, and Transport Properties of the Two Electron-Doped Ruddlesden-Popper Manganites Ca 3 - x Th x Mn 2 O 7. Chem. Mater. 2003, 15 (6), 1302-1308. https://doi.org/10.1021/cm020470n.

(17) Demont, A.; Hébert, S.; Pelloquin, D.; Maignan, A. The Sr2.75Ce0.25Co2O7-ס Oxide, $\mathrm{N}=2$ Member of the Ruddlesden-Popper Series: Structural and Magnetic Evolution Depending on Oxygen Stoichiometry. J. Solid State Chem. 2008, 181 (6), 1314-1320. https://doi.org/10.1016/j.jssc.2008.02.023.

(18) Zhu, J.; Thomas, A. Perovskite-Type Mixed Oxides as Catalytic Material for NO Removal. Appl. Catal. B Environ. 2009, 92 (3-4), 225-233. 
https://doi.org/10.1016/j.apcatb.2009.08.008.

(19) Suntivich, J.; Gasteiger, H. a; Yabuuchi, N.; Nakanishi, H.; Goodenough, J. B.;

Shao-Horn, Y. Design Principles for Oxygen-Reduction Activity on Perovskite

Oxide Catalysts for Fuel Cells and Metal-Air Batteries. Nat. Chem. 2011, 3(7), 546-

550. https://doi.org/10.1038/nchem.1069.

(20) Yu, J.; Sunarso, J.; Zhu, Y.; Xu, X.; Ran, R.; Zhou, W.; Shao, Z. Activity and Stability of Ruddlesden-Popper-Type Lan+1Nin O3n $+1(n=1,2,3$, and $\infty)$ Electrocatalysts for Oxygen Reduction and Evolution Reactions in Alkaline Media. Chem. - A Eur. J. 2016, 22, 1-10. https://doi.org/10.1002/chem.201504279.

(21) Zhang, J.; Zhao, Y.; Zhao, X.; Liu, Z.; Chen, W. Porous Perovskite LaNiO3 Nanocubes as Cathode Catalysts for Li-O2 Batteries with Low Charge Potential. Sci. Rep. 2015, 4 (1), 6005. https://doi.org/10.1038/srep06005.

(22) Wei, Z.; Cui, Y.; Huang, K.; Ouyang, J.; Wu, J.; Baker, A. P.; Zhang, X. Fabrication of La $2 \mathrm{NiO} 4$ Nanoparticles as an Efficient Bifunctional Cathode Catalyst for Rechargeable Lithium-Oxygen Batteries. RSC Adv. 2016, 6 (21), 17430-17437. https://doi.org/10.1039/C5RA23053E. 
(23) Pikalova, E. Y.; Bogdanovich, N. M.; Kolchugin, A. A.; Osinkin, D. A.; Bronin, D. I. Electrical and Electrochemical Properties of La2NiO4+ס-Based Cathodes in Contact with Ce0.8Sm0.2O2-ס Electrolyte. Procedia Eng. 2014, 98, 105-110. https://doi.org/10.1016/j.proeng.2014.12.495.

(24) Woolley, R. J.; Skinner, S. J. Functionally Graded Composite La $2 \mathrm{NiO} 4+\delta$ and La 4 Ni 3 O 10- $\delta$ Solid Oxide Fuel Cell Cathodes. Solid State lonics 2014, 255, 1-5. https://doi.org/10.1016/j.ssi.2013.11.041.

(25) BOEHM, E.; BASSAT, J.; DORDOR, P.; MAUVY, F.; GRENIER, J.; STEVENS, P. Oxygen Diffusion and Transport Properties in Non-Stoichiometric LnNiO Oxides. Solid State lonics 2005, $176 \quad$ (37-38), 2717-2725. https://doi.org/10.1016/j.ssi.2005.06.033.

(26) Gonell, F.; Sanchez-Sanchez, C. M.; Vivier, V.; Méthivier, C.; Laberty-Robert, C.; Portehault, D. Structure-Activity Relationship in Manganese Perovskite Oxide Nanocrystals from Molten Salts for Efficient Oxygen Reduction Reaction Electrocatalysis. Chem. Mater. 2020, 10.1021/ac. https://doi.org/10.1021/acs.chemmater.0c00681. 
(27) Gonell, F.; Alem, N.; Dunne, P.; Crochet, G.; Beaunier, P.; Méthivier, C.; Montero, D.; Laberty-Robert, C.; Doudin, B.; Portehault, D. Versatile Molten Salt Synthesis of Manganite Perovskite Oxide Nanocrystals and Their Magnetic Properties. ChemNanoMat 2019, 5(3), 358-363. https://doi.org/10.1002/cnma.201800632.

(28) Al Raihani, H.; Durand, B.; Chassagneux, F.; Kerridge, D. H.; Inman, D. Zirconia Formation by Reaction of Zirconium Sulfate in Molten Alkali-Metal Nitrates or Nitrites. J. Mater. Chem. 1994, 4 (8), 1331. https://doi.org/10.1039/jm9940401331.

(29) Du, Y.; Inman, D. Reactions of $\mathrm{Zr}(\mathrm{SO} 4) 2$ in Molten Nitrite and Nitrate Systems. J. Mater. Chem. 1995, 5(11), 1927. https://doi.org/10.1039/jm9950501927.

(30) Du, Y.; Inman, D. The Acidic/Basic Effects on Preparation of Zirconia Powders from Molten Salts. J. Mater. Sci. 1996, 31 (13), 5505-5511. https://doi.org/10.1007/BF00360735.

(31) Du, Y.; Inman, D. Synthesis of MgO Powders from Molten Salts. J. Mater. Sci. 1997, 2, 2373-2379.

(32) Jolivet, J.-P. Metal Oxide Chemistry and Synthesis: From Solution to Solid State; Wiley: Chichester, 2000. 
(33) Deshmukh, R.; Niederberger, M. Mechanistic Aspects in the Formation, Growth and Surface Functionalization of Metal Oxide Nanoparticles in Organic Solvents. Chem. - A Eur. J. 2017. https://doi.org/10.1002/chem.201605957.

(34) Afanasiev, P.; Geantet, C. Synthesis of Solid Materials in Molten Nitrates. Coord. Chem. Rev. 1998, 178-180 (PART 2), 1725-1752. https://doi.org/10.1016/s00108545(98)00154-4.

(35) Cui, Z.; Wang, S.; Zhang, Y.; Cao, M. Engineering Hybrid between Nickel Oxide and Nickel Cobaltate to Achieve Exceptionally High Activity for Oxygen Reduction Reaction. J. Power Sources 2014, 272, 808-815. https://doi.org/10.1016/j.jpowsour.2014.08.097.

(36) Stoerzinger, K. a.; Lü, W.; Li, C.; Ariando; Venkatesan, T.; Shao-Horn, Y. Highly Active Epitaxial La(1-x)SrxMnO3 Surfaces for the Oxygen Reduction Reaction: Role of Charge Transfer. J. Phys. Chem. Lett. 2015, 6, 1435-1440. https://doi.org/10.1021/acs.jpclett.5b00439.

(37) Retuerto, M.; Pereira, A. G.; Pérez-Alonso, F. J.; Peña, M. A.; Fierro, J. L. G.; Alonso, J. A.; Fernández-Díaz, M. T.; Pascual, L.; Rojas, S. Structural Effects of 
LaNiO3 as Electrocatalyst for the Oxygen Reduction Reaction. Appl. Catal. B

Environ. 2017, 203, 363-371. https://doi.org/10.1016/j.apcatb.2016.10.016.

(38) Ji, Q.; Bi, L.; Zhang, J.; Cao, H.; Zhao, X. S. The Role of Oxygen Vacancies of ABO

3 Perovskite Oxides in the Oxygen Reduction Reaction. Energy Environ. Sci. 2020,

13 (5), 1408-1428. https://doi.org/10.1039/D0EE00092B. 


\section{Table of contents}

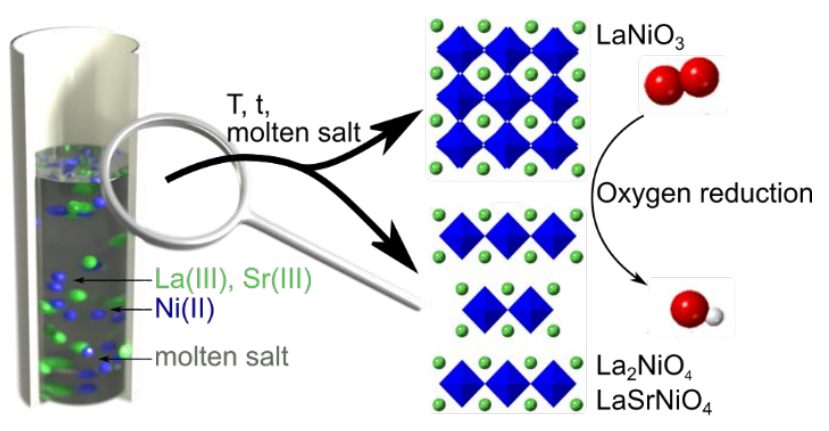

ACS Paragon Plus Environment 